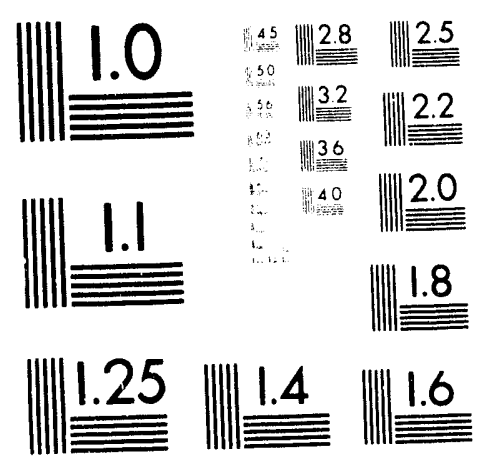



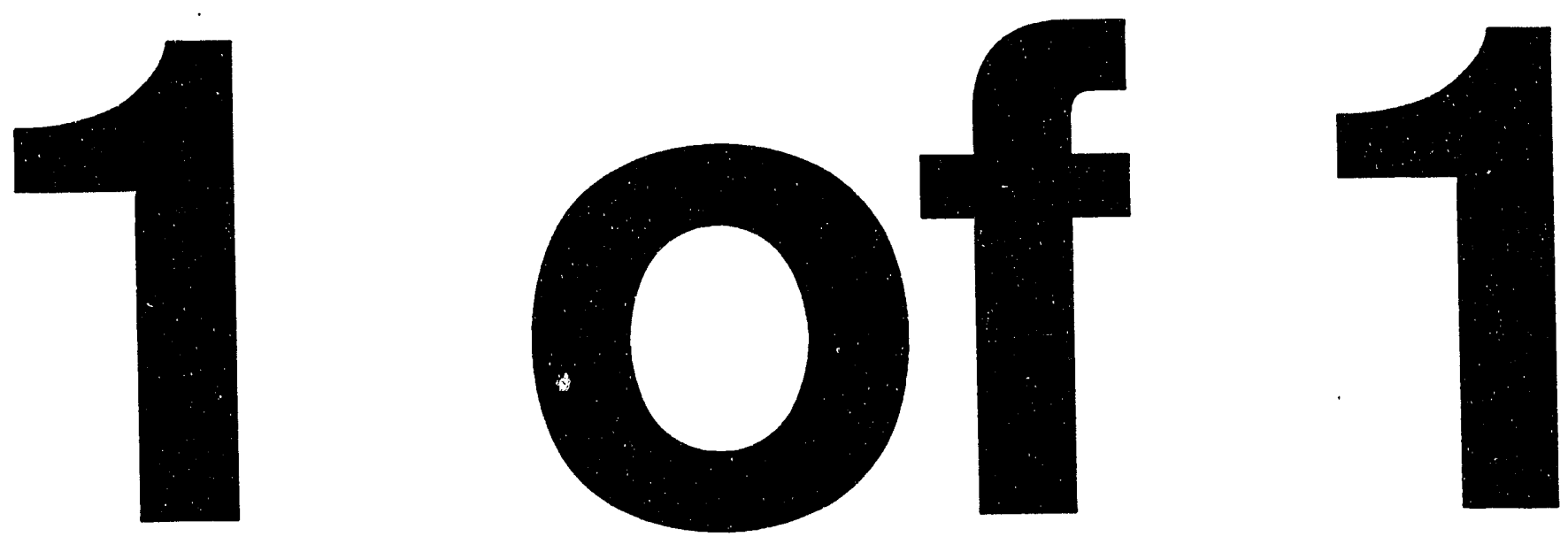


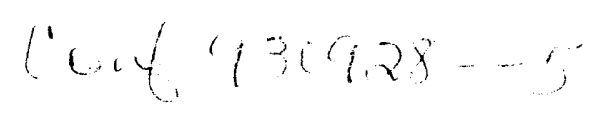

\section{TENSILE STRENGTH OF FIBER REINFORCED PLASTICS AT 77K IRRADIATED BY VARIOUS RADIATION SOURCES}

K. Humer ${ }^{1}$, H. W. Weber ${ }^{1}$, E. K. Tschegg ${ }^{2}$, S. Egusa ${ }^{3}$, R. C. Birtcher ${ }^{4}$, AND H. Gerstenberg $^{5}$

${ }^{1}$ Atominstitut der Österreichischen Universitäten, A-1020 Wien, Austria

2Institut für Angewandte und Technische Physik, TU Wien, A-1040 Wien, Austria

${ }^{3}$ Takasaki Radiation Chemistry Research Establishment, JAERI, Takasaki 370-12, Japan

${ }^{4}$ Materials Science Division, Argonne National Laboratory, Argonne, IL 60439, U.S.A.

5Physik Department E21, TU München, W-8046 Garching, Germany

August 1993

The submited manuscript has been authored by
a contractor of the U.S. Government under
contract No. W-31-109-ENG-38. Accordingly.
the U.S. Government retains a nonexclusive.
royahy-tree license to publish or teproduce the
published form of this contribution, or allow
others to do so, for U.S. Government purposes.

Submitted to the Sixth International Conference on Fusion Reactor Materials (ICFRM), Stresa, Lago Maggiore, Italy, September 27 - October 1, 1993.

*This work supported in part by the Federal Ministry of Science and Research, Vienna, Austria, under contract number 77.800/2-25/92 and by the U. S. Department of Energy, BES-Materials Sciences, under Contract W-31-109-Eng-38.

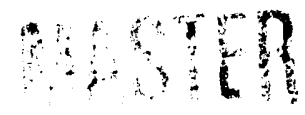


K. Humer, ${ }^{1}$ H.W. Weber, ${ }^{1}$ E.K. Tschegg, ${ }^{2}$ S. Egusa, ${ }^{3}$

R.C. Birtcher, ${ }^{4}$ and H. Gurstenberg 5

${ }^{1}$ Atominstitut der Österreichischen Universitäten, A-1020 Wien, Austria

2Institut für Angewandte und Technische Physik, TU Wien, A-1040 Wien, Austria

3Japan Atomic Energy Research Institute, Takasaki Radiation Chemistry Research

Establishment, Takasaki-shi, Gunma 370-12, Japan

${ }^{4}$ Materials Science Division, Argonne National Laboratory, Argonne, IL 60439, USA

5Fakultät für Physik, E 21, TU München, D-8046 Garching, Germany

\begin{abstract}
The influence of radiation damage on the mechanical properties of fiber reinforced plastics (FRPs), which are considered as candidate materials for the insulation of superconducting magnets for nuclear fusion reactors, has been investigated. Iifferent types of FRPS (epoxies, bismaleimides; two- and three-dimensional reinforcemeit structures with E-, S-, or T-glass fibers) has been included in the test program. Three aspects of our present results will be discussed in detail. The first is related to an assessment of the tensile strength and its radiation dependence under the influence of strongly varying radiation conditions. The second aspect refers to low temperature $(\approx 5 \mathrm{~K})$ reactor irradiation of selected materials. In this case, identical sets of tensile test samples were transferred into the tensile testing machine, one without warming-up to room temperature and the other after an annealing cycle to room temperature. Finally, a comparison between the radiation response of different materials is made. It turns out that the three-dimensionally reinforced bismaleimide shows the smallest degredation of its tensile properties under all irradiation conditions.
\end{abstract}




\section{Introduction}

In view of applications of liber reinforced plastics (FRPS) as insulating materials for the windings of superconducting magnets in fusion reactors $[1-3]$, the mechanical properties of these matsrials have to be tested both at low temperatures and under various loading conditions (e.g. tension and shear) as well as in a radiation environment expected at the magnet location ( $\gamma$-rays and neutrons up to doses of $10^{8}-10^{9} \mathrm{~Gy}$ ). It is well known that $\gamma$ rays and neutrons lead to different damage processes in polymer matrix composites $[4,5]$ Hence, studies of the degradation behavior under pure $\gamma$ - as well as under combined $\gamma$ - and neutron irradiation are important. Several 'nvestigations of radiation damage in FRPs have been reported on previously [6-17].

Some of the most important aspects [18] of irradiation experiments on organic insulating materials should be emphasized. Firstly, the usual testing procedures, i.e. material irradiations in research (fission) reactors, do not provide us with the "right mixture" of radiation. Therefore, different reactor spectra should be investigated, in order to approximate the irradiation conditions of the FRPs in real fusion magnets as closely as possible. Secondly, the radiation damage will be introduced into the materials at the operating temperature of the magnet, i.e. at $\approx 5 \mathrm{~K}$, and several thermal cycles to room temperature will occur over the life time of the magnet. Thirdly, because of space limitations in existing (low) temperature irradiation facilities, all of the mechanical tests have to be done on samples which are smaller than those of the established standards.

In view of this situation, a series of irradiation experiments has been initiated, the first results of which are reported on in the present paper. Different types of FRPs (two or three dimensional E-, S- or T-glass fiber reinforcement, epoxy or bismaleimide resin) have been irradiated at room temperature by $2 \mathrm{MeV}$ electrons and ${ }^{60} \mathrm{Co}$-gamma rays up to $1.8 \times 10^{8} \mathrm{~Gy}$ and by different gamma and neutron fission spectra up to neutron fluences of $5 \times 10^{22} \mathrm{~m}^{-2}$ $(E>0.1 \mathrm{MeV})$ and $\gamma$-dose levels of $\approx 2 \times 10^{8} \mathrm{~Gy}$. Tensile tests were carried out on the irradiated samples at $77 \mathrm{~K}$, in order to investigate the influence of these different radiation 
environments on the mechanical properties. After $5 \mathrm{~K}$ irradition, some tensile samples were tested at $77 \mathrm{~K}$ with and without annealing cycles to room temperature.

\section{Experimental}

As mentioned above, due to space limitations in existing (low temperature) irradiation facilities, all of the mechanical tests have to be done on small specimens, which can lead to serious problems. Whenever inhomogeneous materials (e.g. concrete) are tested, "sizeeffects" have to be investigated in much detail [19]. Earlier studies [20-25] on various FRPs have shown that specific sample dimensions can indeed influence the measured mechanical quantities. Therefore, extensive scaling experiments were made at room temperature on tensile samples $[22,23]$, in order to select a small specimen geometry for low temperature experiments on irradiated samples. These tests have shown only small variations (10-20\%) of the ultimate tensile strength and of the specific fracture energy with sample dimensions and have, therefore, led to satisfactory results. The geometry and the dimensions of the tensile specimen have been presented elsewhere $[22,23]$.

All mechanical tests were carried out at $77 \mathrm{~K}$ using a stiff tensile testing machine. The crosshead speed was kept constant at $0.5 \mathrm{~mm} \mathrm{~min}^{-1}$ throughout all experiments. During ine tensile measurements, both the force and the sample elongation were recorded on an $\mathrm{XY}$ recorder.

For the present experiments, the following FRPs have been investigated. Two-dimensional woven S-glass fabric/epoxies ISOVAL 10/S (Isovolta AG, Wiener Neudorf, Austria) and CTD-101 (Composite Technology Development Inc., Boulder, Colorado, USA); twodimensional E-glass fabric/epoxies ORLITHERM N (Asea Brown Boveri Ltd., Zürich, Switzerland) and EPO-HGW (Elin Energieanwendung GesmbH., Weiz, Austria) as well as the three-dimensional T-glass fabric/epoxy and bismaleimide triazine resin ZI-003 and ZI005 (Shikibo Ltd., Yokaichi-shi, Shiga, Japan). 
The samples were cut from plates of different thickness ( $1 \mathrm{~mm}$ for CTD-101, ZI-003 and ZI-005; $2 \mathrm{~mm}$ for ISOVAL 10/S, ORLITHERM $\mathrm{N}$ and EPO-HGW) with their lengths parallel to the direction of the fiber orientation with the higher fiber content. Two samples were measured for each data point.

\section{Results - Room temperature irradiation of various radiation sources}

In order to obtain a first overview of the radiation response of all materials, $2 \mathrm{MeV}$ electron irradiation (JAERI, Takasaki) was carried out at room temperature up to a dose of $1.8 \times 10^{8} \mathrm{~Gy}$.

The results on the ultimate tensile strength (UTS) as a function of absorbed dose are summarized in Fig.1. Beginning with the three-dimensional fiber reinforced plastics (3DFRPs), we note that ZI-005 shows a higher radiation resistance than ZI-003. Whereas for the bismaleimide first degradations in the UTS (about 20\%) are observed in the range from 1.4 to $1.8 \times 10^{8} \mathrm{~Gy}$, significant degradation takes place in the epoxy already at 2.0 $8.0 \times 10^{7} \mathrm{~Gy}$. At higher dose levels, the epoxy is destroyed completely and the measured UTS results from the glass fibers, which are oriented in the direction of the tensile load. Hence, no further reduction of the UTS is observed at higher dose levels up to $1.8 \times 10^{8} \mathrm{~Gy}$. The results on the 2DFRPs (all epoxies) demonstrate the influence of different compositions of the composite compounds (glass fibers and epoxies). CTD-101 shows the best values of the UTS at all doses and the final reduction amounts to about $35 \%$ at $1.8 \times 10^{8} \mathrm{~Gy}$. Furthermore, different epoxy compositions lead to significantly different strength values (ORLITHERM N - EPO-HGW). For these FRPs, the reduction of the UTS amounts to about $70 \%$ and leads to unacceptable strength values at high doses. Finally, a comparison of the dose dependence reveals that the radiation resistance increases in the order EPO-HGW $\rightarrow$ ORLITHERM N $\rightarrow$ CTD-101 $\rightarrow$ ZI-003 $\rightarrow$ ZI-005. 
Based on these results, the influence of different reactor spectra (gamma rays and neutrons) on the UTS was investigated for the "best" three FRPS. In this case, all samples were irradiated at room temperature at different radiation sources as follows: Up to neutron fluences of $1 \times 10^{21}, 1 \times 10^{22}$ and $5 \times 10^{22} \mathrm{~m}^{-2}(\mathrm{E}>0.1 \mathrm{MeV})$ in the TRIGA Mark II reactor Vienna $\left(\gamma\right.$-dose rate: $\left.\approx 10^{6} \mathrm{Gyh}^{-1}\right)$, up to $1.5 \times 10^{21}, 2.3 \times 10^{21}$ and $7.8 \times 10^{21} \mathrm{~m}^{-2}(\mathrm{E}>0.1 \mathrm{MeV})$ at the Intense Pulsed Neutron Source (IPNS) at Argonne National Laboratory ( $\gamma$-dose rate: $\approx 2 \times 10^{4} \mathrm{Gyh}^{-1}$ ). Furthermore, pure ${ }^{60} \mathrm{Co} \gamma$-irradiation was done (JAERI, Takasaki) up to absorbed doses of 3.6 and $36 \times 10^{6} \mathrm{~Gy}\left(\approx 1.35 \mathrm{Mr} \mathrm{h}^{-1}\right)$. The dose dependence of the UTS measured on ZI-005, ZI-003 and CTD-101 under these conditions is shown in Fig.2. We wish to point out that the observed radiation damage is almost identical for all radiation sources in all composites investigated. The overall effects are in the range from $20 \%$ (CTD-101) to $40 \%$ (ZI-003). Again the bismaleimide resin shows better radiation resistance than the epoxies.

This remarkable agreement between different radiation environments can be attributed to the following two facts. Firstly, all of the reactor irradiation experiments made so far, were carried out on materials containing boron-free glass. Hence, the specific damage process related to the boron $n, \alpha$-reaction did not contribute to the degradation of the tensile properties, even in the case of neutron irradiation. This aspect of the radiation environment is currently being investigated in a seperate program. Secondly, due to the availability of detailed information on the neutron spectra of each irradiation source [26], the energy deposited by the neutrons in the resins could be assessed accurately through the computer code SPECTER [27]. The corresponding procedure can be illustrated in the following way.

For a resin with a composition of $15 \mathrm{wt} \% \mathrm{H}, 75 \mathrm{wt} \% \mathrm{C}, 3 \mathrm{wt} \% \mathrm{~N}$, and $7 \mathrm{wt} \% \mathrm{O}$, irradiated in the TRIGA reactor to a fast neutron fluence of $5 \times 10^{22} \mathrm{~m}^{-2}(\mathrm{E}>0.1 \mathrm{MeV})$, the energy deposited by the neutrons is calculated by the computer code for each constituent individually and than added up. The results for the above resin and fluence (which corresponds to a total fluence of $1.38 \times 10^{23} \mathrm{~m}^{-2}$ ) are as follows: $\mathrm{H}-1.7 \times 10^{8} \mathrm{~Gy}, \mathrm{C}-1.3 \times 10^{7}$ Gy, $\mathrm{N}-1.9 \times 10^{6} \mathrm{~Gy}, \mathrm{O}-1.1 \times 10^{5} \mathrm{~Gy}$, i.e. a total of $1.85 \times 10^{8} \mathrm{~Gy}$. In addition, during the 
irradiation time of 183 hours needed to achieve the above fluence of neutrons, a gamma dose of $1.83 \times 10^{8} \mathrm{~Gy}$ was accumulated, i.e. the total dose (gamma and neutrons) amounts to $3.58 \times 10^{8} \mathrm{~Gy}$. For this radiation source and for this particular composition of the test material, both kinds of radiation contribute $=50 \%$ to the total dose. For another material, e.g. one with $5 \mathrm{wt} \% \mathrm{H}, 73 \mathrm{wt} \% \mathrm{C}, 10 \mathrm{wt} \% \mathrm{~N}$, and $12 \mathrm{wt} \% \mathrm{O}$, the relative contributions are significantly different and amount to $0.76 \times 10^{8} \mathrm{~Gy}$ (neutrons $30 \%$ ) and to $1.82 \times 10^{8} \mathrm{~Gy}$ (gammas $70 \%$ ), i.e. a total of $2.58 \times 10^{8}$ Gy under exactly the same irradiation conditions.

\section{Results - $5 \mathrm{~K}$ irradiation and annealing effects}

Irradiation experiments employing low temperature irradiation and testing at $77 \mathrm{~K}$ with and without an annealing cycle to room temperature were done as well. Some tensile samples (ZI-005, ZI-003 and CTD-101) were irradiated at the $5 \mathrm{~K}$-irradiation facility of the FRM Munich up to neutron fluences of $1 \times 10^{21}, 1 \times 10^{22}$ and $5 \times 10^{22} \mathrm{~m}^{-2}(\mathrm{E}>0.1 \mathrm{MeV}, \gamma$-dose rate $\left.2.8 \times 10^{6} \mathrm{Gyh}^{-1}\right)$. After $5 \mathrm{~K}$ irradiation, some of the samples were subjected to a warm-up cycle ( $\approx 1 \mathrm{~h}$ at room temperature) before testing at $77 \mathrm{~K}$. The results are summarized in Fig.3. No systematic influence of the annealing cycle could be detected. In addition, the degradation of the ultimate tensile strength is almost identical to the one observed upon room temperature irradiation of the same materials.

\section{Conclusions}

A series of irradiation experiments has been started, in order to clarify the role of the radiation spectrum in the damage process of FRPs. Different types of FRPs (two or three dimensional E-, S- or T-glass fiber reinforcement, epoxy or bismaleimide resin) were irradiated at room temperature with $2 \mathrm{MeV}$ electrons and ${ }^{60} \mathrm{Co} \gamma$-rays up to $1.8 \times 10^{8} \mathrm{~Gy}$ and with different reactor spectra up to fast neutron fluences of $5 \times 10^{22} \mathrm{~m}^{-2}(\mathrm{E}>0.1 \mathrm{MeV})$ prior to tensile testing of the irradiated samples at $77 \mathrm{~K}$. 
The main results of these irradiation experiments are the following:

1. With regard to material selection, the three-dimensional fiber reinforcement and the bismaleimide resin show higher radiation resistance than the two-dimensional reinforcement and the epoxies under tensile loading conditions. The decrease of the ultimate tensile strength varies between $35 \%$ and $70 \%$.

2. With regard to the influence of the radiation spectrum (electrons, neutrons and/or $\gamma$-rays) on the ultimate tensile strength, no significant difference in the dose dependence is observed and the overall effects are between 20 and $40 \%$ in the "best" materials.

3. This "scaling" of the ultimate tensile strength data with absorbed dose is attributed to a correct assessment of the energy deposited by the neutrons and to the absence of boron in the reinforcing glass.

4. Tensile tests made after $5 \mathrm{~K}$ irradiation do not differ significantly from the results obtained after room temperature irradiation. This holds for "cold-transfer" tests $(5 \mathrm{~K} \rightarrow 77 \mathrm{~K})$ as well as for tests including an annealing cycle to room temperature $(5 \mathrm{~K} \rightarrow 293 \mathrm{~K} \rightarrow 77 \mathrm{~K})$.

\section{Acknowledgements}

The authors are greatly indebted to Asea Brown Boveri Ltd., Zürich, Switzerland (ORLITHERM N); Composite Techriviogy Development Inc. , Boulder, Colorado, USA (CTD-101); Elin Energieanwendung GesmbH., Weiz, Austria, (EPO-HGW); Isovolta AG, Wiener Neudorf, Austria, (ISOVAL 10/S); and Shikibo Ltd., Yokaichi-shi, Shiga, Japan (ZI-003 and ZI-005), for providing us with the test materials. One of us (K.H.) wishes to thank JAERI for the hospitality during a two months visit to Takasaki. The cooperation of Dr. H. Nakajima (JAERI-Naka Laboratory) and technical support by Mr. H. Niedermaier and Mr. E. Tischler (Vienna) is acknowledged. This work is supported in part by the Federal Ministry of Science and Research, Vienna, Austria, under contract \# 77.800/225/92 and by the U.S. Department of Energy, BES-Materials Sciences, under contract W1-109-Eng-38. 


\section{References}

(1) B.S. Brown, J. Nucl. Mat. 97 (1981) 1.

12] "Insulators for Fusion Applications", It.EA-TECDOC-417, IAEA, Vienna (1987).

[3] R.R. Coltman, jr., J. Nucl. Mat. 108\&109 (1982) 559.

[4] S. Egusa, M.A. Kirk, and R.C. Birtcher, J. Nucl. Mat. 148 (1987) 43.

[5] S. Egusa, M.A. Kirk, and R.C. Birtcher, J. Nucl. Mat. 148 (1987) 53.

[6] S. Egusa and M. Hagiwasa, Cryogenics 26 (1986) 417.

[7] G.F. Hurley and R.R. Coltman, jr., J. Nucl. Mat. 122\&123 (1984) 1327.

[8] S. Nishijima, T. Okada, T. Hirokawa, J. Yasuda, and Y. Iwasaki, Cryogenics 31 (1991) 273.

[9] S. Egusa, J. Mat. Sci. 25 (1990) 1863.

[10] R.R. Coltman, jr. and C.E. Klabunde, J. Nucl. Mat. 103\&104 (1981) 7.

[11] S. Egusa, Radiat. Phys. Chem. 37 (1991) 147.

[12] S. Egusa, M.A. Kirk, R.C. Birtcher, and M. Hagiwara, J. Nucl. Mat. 127 (1985) 146.

[13] S. Nishijima and T. Okada, Cryogenics 18 (1978) 215.

[14] S. Egusa, Cryogenics 31 (1991) 7.

[15] H.W. Weber, E. Kubasta, W. Steiner, H. Benz, and K. Nylund, J. Nucl. Mat. 115 (1983) 11.

[16] R.E. Fornes, J.D. Memory, and N. Naranong, J. Appl. Poly. Sci. 26 (1981) 2061.

[17] S. Egusa, M.A. Kirk, R.C. Birtcher, and M. Hagiwara, J. Nucl. Mat. 133\&134 (1985) 795.

[18] H.W. Weber and E.K. Tschegg, Adv. Cryog. Eng. 36 (1990) 863.

[19] P. Zdenek and P. Bazant, J. Eng. Mech. 110 (1984) 518.

[20] E.K. Tschegg, K. Humer, and H.W. Weber, Adv. Cryog. Eng. 38A (1992) 387.

[21] E.K. Tschegg, K. Humer, and H.W. Weber, Adv. Cryog. Eng. 38A (1992) 355.

[22] E.K. Tschegg, K. Humer, and 1..W. Weber, Cryogenics 31 (1991) 312.

[23] K. Humer, E.K. Tschegg, H.W. Weber, K. Noma, J. Yasuda, and Y. Iwasaki, Cryogenics 33 (1993) 162. 
[24] K. Humer, E.K. Tschegg, and H.W. Weber, Cryogenics (ICMC Supplement) 32 (1992) 14.

[25] E.K. Tschegg, K. Humer, and H.W. Weber, J. Mat. Sci. 28 (1993) 2471.

[26] H.W. Weber, H. Böck, and E. Unfried, J. Nucl. Mat. 137 (1986) 236.

[27] L.R. Greenwood and R.K. Smither, SPECTER: Neutron damage calculations for materials irradiations, ANL/FPP/TM-197 (1985). 
Figure Captions

Figure 1. Ultimate tensile strength of ZI-005, ZI-003, CTD-101, ORLITHERM N and EPO-HGW as a function of the absorbed dose following room temperature irradiation with $2 \mathrm{MeV}$ electrons and fracture at $77 \mathrm{~K}$.

Figure 2. Ultimate tensile strength of ZI-005, ZI-003 and CTD-101 as a function of the total absorbed dose following room temperature irradiation with different spectra and fracture at $77 \mathrm{~K} . \mathrm{UTS}_{0}$ is the ultimate tensile strength prior to irradiation.

Figure 3. Ultimate tensile strength of ZI-005, ZI-003 and CTD-101 as a function of the total absorbed dose following $5 \mathrm{~K}$ irradiation (neutrons and $\gamma$-rays) with and without a warm-up cycle to room temperature before testing at $77 \mathrm{~K}$. 


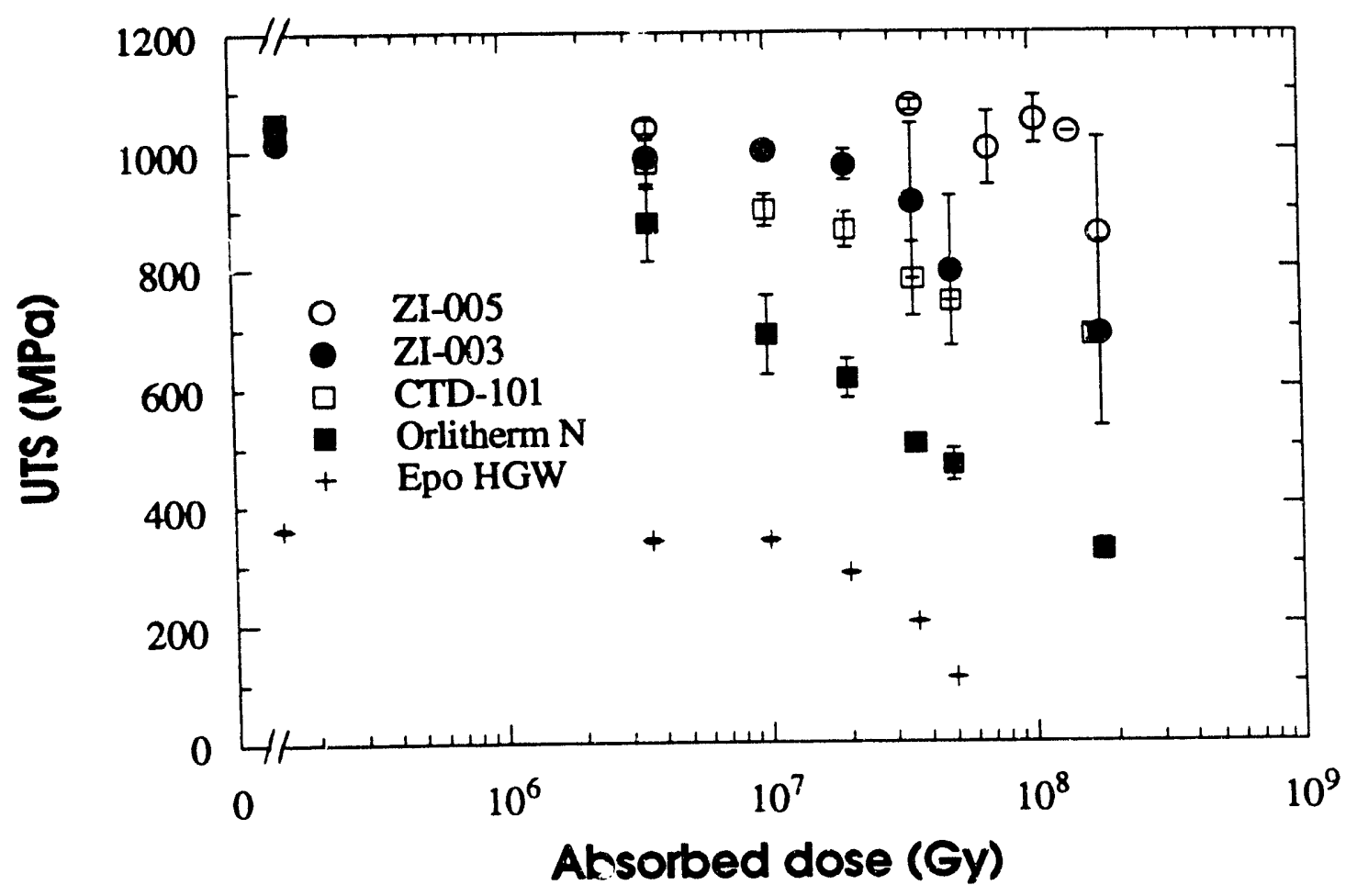



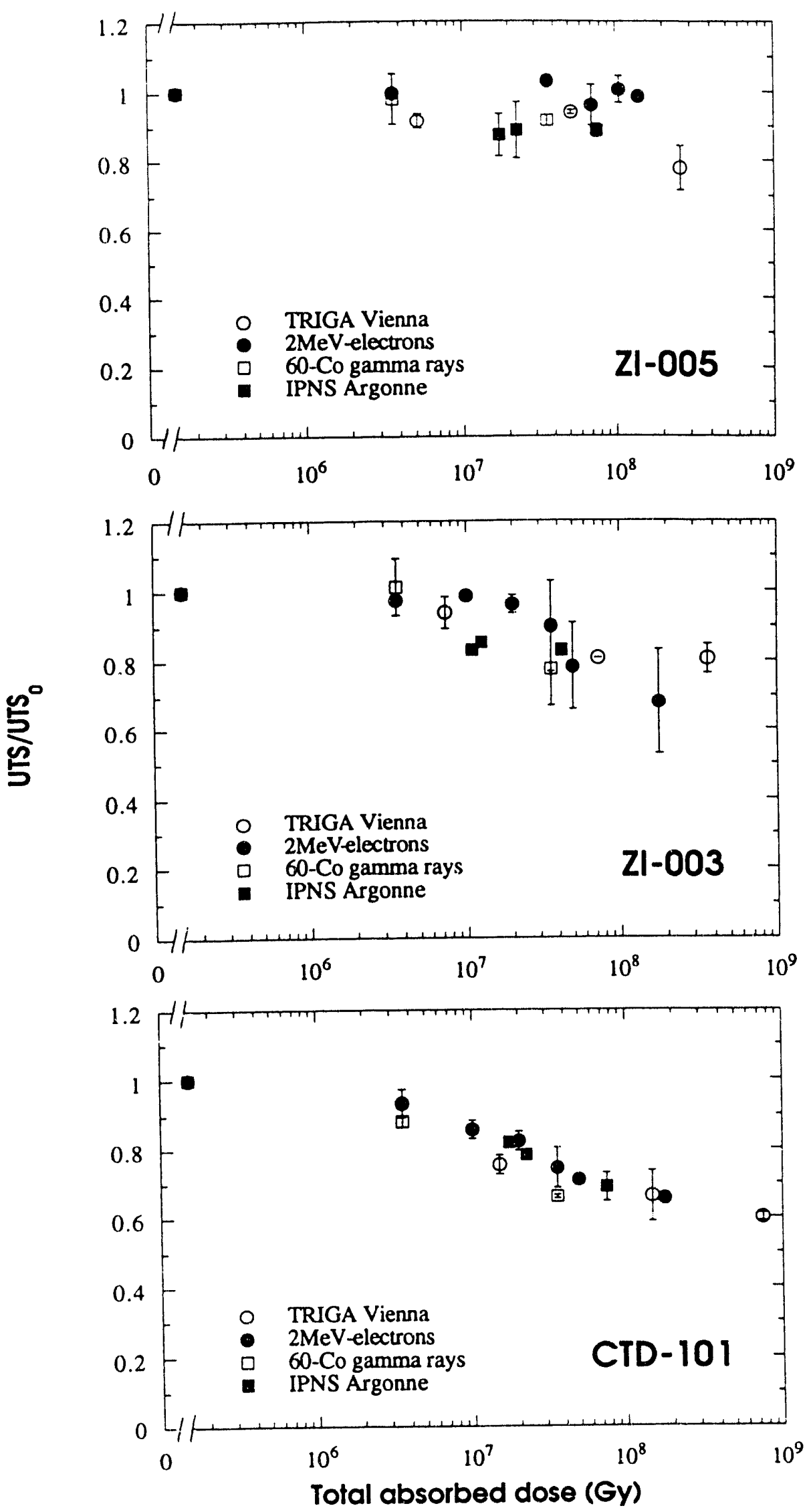

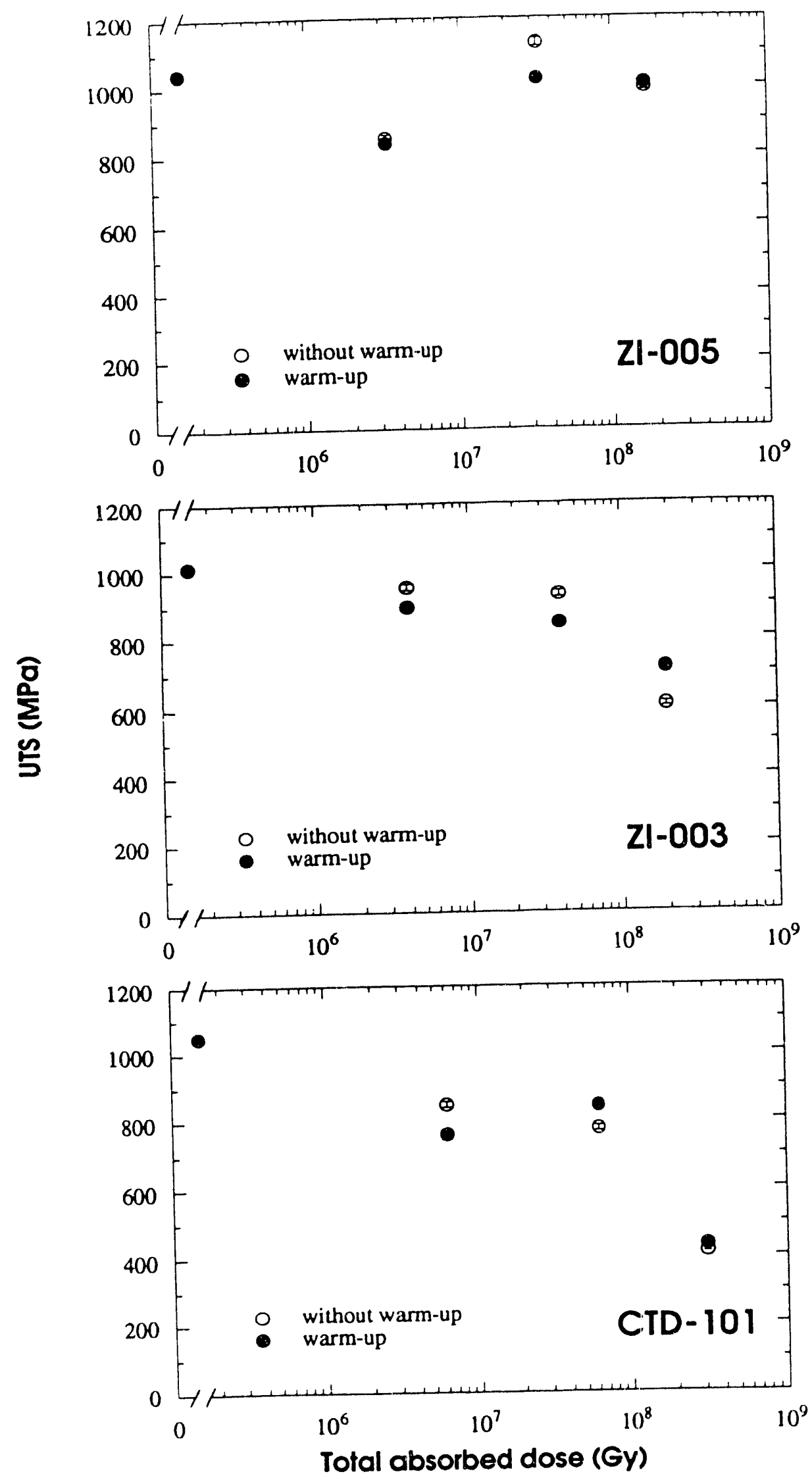

$F: 0$ 

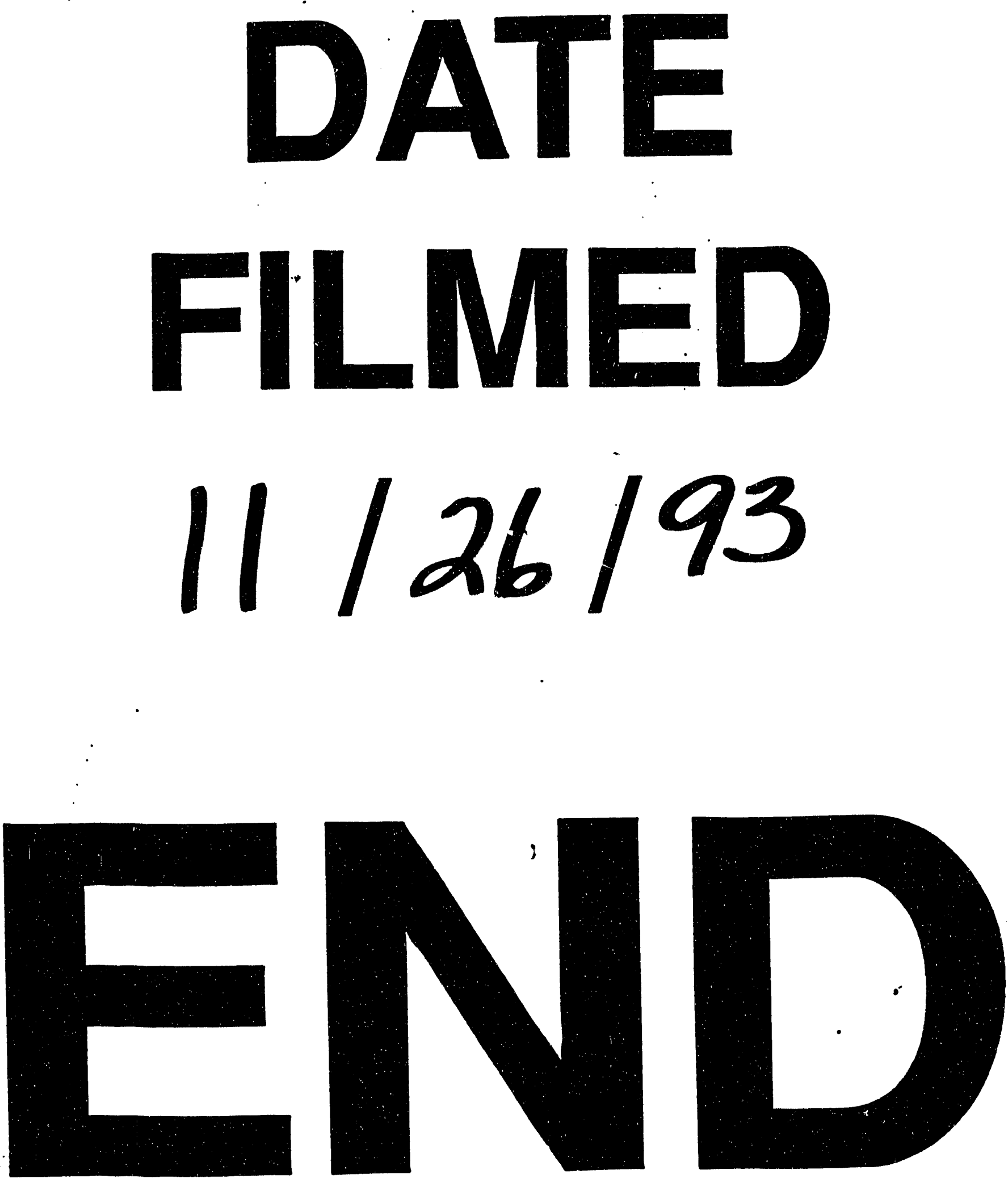
